\title{
Defensive mechanisms in Plants: The role of component plant cells in defense against biotic and abitic stresses
}

\author{
Firoozeh Chamandoosti
}

Iranian Research Institute of Plant Protection, Agricultural Research, Education and Extension Organization (AREEO), Tehran, Iran

$\mathrm{PhD}$ of Cellular and Developmental Biology, Assistant Professor of Iranian Research Institute of Plant Protection Department of Plant Diseases

\begin{abstract}
Plants are often exposed to various environmental stresses such as extreme temperatures, drought, and disease and pest attack. In natural systems, plants face a plethora of antagonists and thus posses a myriad of defense and have evolved multiple defense mechanisms by which they are able to cope with various kinds of biotic and abiotic stresses. In fact plants defense against stresses by different ways. The role of cellular organelles is very important in this way. Cell wall and their derivatives such as oligosaccharins as biochemical defenser or for example trichomes as mechanical defenser is the frontline of the plant defense system. Also Plants have evolved a multi-layered immune system that dynamically responds to pathogens alike cell membrane that is a key mediator of communication between plants and microbes. Cytoplasm and the membrane-bounded structures (organelles) defense against different kind of stresses. The role of cellular organelles in plant defense relate to their enzymes primarily. Enzymes such as proteases, esterases and ribonucleases in cytoplasm, PM H+ATPases in plasma membrane or $\beta$ glucosidases included cyanogenic glucosides, saponins, glucosinolates or DIMBOA (2,4dihydroxy-7-methoxy-1,4-benzoxazin-3-one) glucoside in ER are responsible for plant defense. Also ROSs plus SA and JA in chloroplast and mitochondria play an important role in immune plant system. In nucleus macromolecules including nucleoporins, importins, and Ran-GTP-related components, are essential to mount an efficient immune response in response to different pathogens. And in Golgi apparatus, peroxysomes and vacuoles, glycosyltransferases, myrosinase and hydrolytic enzymes are liable for plant defense respectively.
\end{abstract}

Keywords — biotic and abiotic stresses; organells; plant defense.

\section{INTRODUCTION}

Despite of enormous differences in living organisms, all of them have similar characteristics. These similar characteristics that are signs of living organisms are known by us since primary school, respiration, nutrition, reproduction but among living organisms, plants have a very special characteristic that is photosynthesis. Briefly photosynthesis is a process used by plants to convert light energy into chemical energy that can later be released to fuel the organisms' activities (energy transformation). Also Photosynthesis is largely responsible for producing and maintaining the oxygen content of the Earth's atmosphere, and supplies all of the organic compounds and most of the energy necessary for life on Earth (Bryant and Frigaard 2006). It is noticeable that in nature algae and cyanobacteria, are photoautotroph also. But plants are important means of livelihood and production of human beings. So the relations between plants and human beings are also very close (Anant et al., 2013). Thought to be the importance of plants well informed by this short preface till now.

Like all of living organisms plants are continuously subjected to stresses. Stresses in plants are classified by different form but all of stresses are abiotic or biotic generally. An abiotic stress can be a mechanical injury. But biotic stresses in plants refer to plant diseases or phyto-pathogens (Doughari 2015). Plant diseases refer to any disturbance in functioning and growth that cause a lower operating efficiency or a breakdown in the plant's metabolism. Diseases afflict plants generally result from microbial infections, invasions of the body by pathogenic viruses, bacteria, fungi, or other microorganisms (Dickison 2000). Pests are biotic stresses and are often included insects. Furthermore nematode worms can sicken plants. According to statement plants must campaign against these devastating agents. In this review different defensive mechanisms for survival are noticed in plants. Also in this review the classification of different defensive mechanism will base on defense by cellular and subcellular components.

\section{DEFENSIVE MECHANISMS IN PLANTS}

It is clear that plants unlike vertebrate haven't a sophisticated immune system that provides the body with a means of resistance infection (Dickison 2000). In natural systems, plants face a plethora of antagonists and thus posses a myriad of defense and have evolved multiple defensive mechanisms by which they are able to cope with various kinds of biotic and 
abiotic stresses. There are many factors that affect on defense in plants for example age of plants, type of organ infected, nutritional status of the host and environmental conditions (Gianinazzi and Ahl 1983).

So plants have an innate immunity of each cell and produce systemic signals emanating from the infection site. On the other hand plants defense against unfavorable condition by all of their compartments and organelles.

These compartments include in cell wall, plasmalmma, Endoplasmic reticulum, mitochondria, chloroplast, cytoplasm, Golgi apparatus, peroxysomes and vacuoles.

\section{DefenSe BY Cell Wall}

The frontline of the plant defense system is cell wall. Cell wall is one of the most distinctive structural features of plant cells is the surrounding wall, characteristically composed of the carbohydrate cellulose deposited in fibrillar form (Dickison 2000).

One of the important ways of plant defense by cell wall are oligosaccharins. Oligosaccharins are fragments of the plant cell wall that serve as regulatory molecules. They help to control such functions as growth, development, reproduction and defense against disease. For example some oligosaccharins, such as oligogalacturonids, act as elicitors and evoke pathogen defense responses. These defense responses include the accumulation of phytoalexins, proteinase inhibitors, lignin, peroxidase, lipoxygenase (LOX) and $\beta-1,3$ glucanases (Ryan, 1988; Hahn et al., 1989; Ebel and Cosio, 1994). These bioactive, are relatively easy to produce and ready to face public acceptance because of their natural origin. Also oligosccharins have practical use in agriculture. So that oligogalacturonides, prepared from citrus pectin, that can partial or totally substitute phytohormones in the culture "in vitro" of sugar cane, citrus, coffee, tomato, rice and banana plants, reducing the time required for plant propagation, avoiding culture-induced genetic changes and increasing field survival percentage of these plants but also inducing rooting and plant growth (Saa Silva et al.. 2013).

It is clear that the shape and integrity of a fungus is also dependent upon the mechanical strength of its cell wall, which performs a wide range of essential roles during its interaction with its environment. The fungal cell wall is a complex structure typically composed of chitin, and glucan, mannan and proteins, although its composition frequently varies between species of fungi (Dhume et al., 1993). Both, plant and fungal cell walls, are a major target of the same type of cell wall degrading enzymes acting in the early stages of the plant-pathogen interaction. Additionally, oligosaccharides released from this degradation of plant or fungal cell walls can play the role of signaling molecules activating defenses responses and enhance growth or development in plants (Sea Silva et al.. 2013).

The role of cell wall in defense mechanisms in plant has been proved by cellulose deficient mutants. These mutants typically exhibit increased lignifications (Malinovsky et al., 2014). Interestingly, these changes appear to have effects beyond the purely structural. Such mutants also display enhanced defense responses (Hamann et al., 2009).

The another outer surface covering of the plant cell is cuticle that is multilayered mass in young stems and foliage consisting an insoluble polyester called cutin (Dickison 2000). Cuticle is a very effective barrier to invasion by pathogenic microbes (Dickison 2000). Not only biotic and abiotic stresses but also water loss is protected by cuticle in plants (Mario et al., 2014). The cuticle is structurally diverse among species but exhibits the organization of a composite material consisting in cutin, a polyester that is partly covered and interspersed with waxes (epicuticular and intracuticular waxes) (Mario et al., 2014). The roles of cuticle function in defensive mechanisms in plants are cleared when we study about mutants with specific defects in cutin. These mutants show an altered ultra structure of the cuticle and an enhanced permeability of the cuticle to solutes In addition, pollen could germinate on fully differentiated leaves of cutinase-expressing plants but not on control leaves. (Patrick et al., 2000). This finding is implied that cutin is important for preventing fusions between different plant organs and is therefore necessary for normal epidermal differentiation and organ formation (Heid 1991; Walker and .Bruck 1985). So the cuticle is the contact zone between the plant and the environment and its physical properties are highly relevant to the functions of the epidermis (Kerstiens 1996a; 1996b).

Some of the epidermal cells of most plants grow out in the form of hairs or trichomes. They may be found singly or less frequently in groups. They may be unicellular or multicellular and occur in various forms. They vary from small protuberances of the epidermal cells to complex branched or satellite multicellullar structures. The cells of the hairs may be dead or living.

In some plants the role of trichomes is minimizing invasion of specific pathogens (Dickison 2000). Actually leaf trichome density is considered a mechanism of defense in plants to prevent or diminish damage by herbivores (Levin, 1973; Johnson, 1975; Rodriguez et al., 1984; Juniper and Southwood, 1986; Marquis, 1992) Evidence from wild and cultivated species gives 
support to this ecological role (Duffey, 1986; Jeffree, 1986; David and Easwaramoorthy, 1988; Woodman and Fernandes, 1991; Bernays and Chapman, 1994; Peter et al., 1995; Romeis et al., 1999). The most important role of trichomes in plant defense is resistance against natural herbivores. Besides defense, leaf trichomes may serve other physiological functions, hence selection on the antiherbivory role of leaf trichome density can either be constrained or synergistically favored by selection imposed by other environmental stresses (Bell, 1997; Roy et al., 1999).

Alike trichomes thorns are a part of the defensive mechanism in plants. A thorn is a loose term for any sharp, pointed appendage coming off a plant for defensive purposes. Botanically, thorns can also be called spines (modified leaves), prickles (sharpened branches) or trichomes based on their location on the plant. Thorns are essentially defense mechanisms for the plant, The sharp points protect the plant against animals that want to eat it. There is an interesting experiment that have conducted by cut branches of three woody species that had their thorns removed suffered significantly greater herbivory by a tethered goat than did paired intact branches (Milewski et al., 1990).

Moreover smells, oils, thick and waxy skin, intact outer periderm or bark of woody plants provide sufficient barrier for plant defense against stresses by different methods for example some plants emit different smells to repel animals or others excrete oils to kill other plants. Also there are plants that have thick skin to keep from dehydrating. Trees have different types of bark to help deal with cold or hot environments. It is important that we know plants don't use one defensive strategy. Plants have all kind of strategies for protect themselves from difficult conditions (Milewski et al., 1990).

\section{Defense by Plasma Membrane}

Plants have evolved a multi-layered immune system that dynamically responds to pathogens. Most classes of plant pathogens remain outside the host cell membrane during their lifecycle. As a result, the plant plasma membrane (PM) is a key mediator of communication between plants and microbes (James and Gitta 2011). Initial pathogen recognition occurs at the PM and many of the earliest cellular responses to microbial invasion are controlled by PM-localized enzymes and ion channels (Boller and Felix, 2009).

In addition, multiple downstream responses to pathogen stimuli are executed at the plasma membrane. Pathogens must manipulate host cells in order to suppress these defense responses and procure nutrients. It is therefore expected that membrane transport processes have numerous functions in compatible (susceptible) and incompatible (resistant) interactions (Hahn and Mendgen, 2001; Ward et al., 2009).

Also it is noticeable that in plants, PM H+-ATPases are the primary pumps responsible for the establishment of cellular membrane potential. Plant PM H+-ATPases use energy derived from ATP hydrolysis to pump protons from the cytosol to the extracellular space, thus creating and maintaining a negative membrane potential and a transmembrane $\mathrm{pH}$ gradient (acidic outside). This proton electrochemical gradient can control multiple aspects of transport across the PM. PM $\mathrm{H}^{+}$ATPase activity is dynamically regulated during plant immune responses and multiple pathogens target this family of enzymes during infection (James and Gitta 2011).

\section{DEFENSE BY CYTOPLASM}

The cytoplasm of eukaryotic cells consists of all cell material between the nucleus and the plasma membrane and contains membrane-bounded structures, organelles, which are embedded in the cytosol consisting of water, salts and organic molecules, including sugars, proteins and many enzymes that catalyze reactions. The cytoskeleton of microtubules and actin filaments in the cytosol structures the cell by localizing and transporting the organelles bound to these tubules and filaments. The plasma membrane, enveloping the cytoplasm physically, separates the cell content from the extra-cellular environment, which in plant cells is the cell wall (Esseling-ozdona et al., 2008).

Also cytoplasm is an important barrier for plants defense. The earliest cytoplasmic response to contact between a micro organism and host cell is cyclosis within the protoplast, with a resultant reorganization of cytoplasmic organelles. Infection of tuber tissues and tissue culture cells of Solanum tuberosum by Phytophthora erythroseptica, P. infestans and Fusarium caeruleum caused swelling and disruption of host cytoplasmic particles containing acid phosphatases, esterases and proteases. Heavy diffuse cytoplasmic staining for acid phosphatase was a consistent feature of infection by the three fungi, but staining reactions for esterase and protease showed much less diffuse staining and a lesser degree of particle swelling. An excess recovery of ribonuclease from tissues infected with $P$. infestans and $F$. caeruleum was found. An electrophoretic comparison of near isogenic lines of wilt resistant (Fusarium oxysporum f.sp. pisi) or susceptible Pisum sativum was made. 
The resistance lines differed from susceptible lines in carrying an esterase component with has been derived from the resistant cultivar Delwich Commando (Dhan Pal and Arti, 2005).

\section{DEFENSE BY ENDOPLASMIC RETICULUM}

The endoplasmic reticulum (ER) is a network-like structure that is bound by a single membrane. The ER is a dynamic organelle composed of various functional domains (Staehelin 1996). It includes the rough ER (rER), smooth ER (sER) and nuclear envelope. The rER is a well-understood organelle that is coated by ribosomes and is responsible for the synthesis of secretory proteins. The sER has no ribosomes but instead accumulates a series of lipid biosynthesis enzymes. In addition, the ER accumulates specific types of seed storage proteins, such as prolamin or zein, to produce protein bodies (PBs) in the endosperm of some plants. (Herman 2008, Yasuda et al. 2009, Kumamaru et al., 2010, Satoh-Cruz et al. 2010, Nagamine and Okita, 2011).

Several lines of evidence suggest that ER bodies are involved in defensive mechanisms in plants. Wounding or application of the wound hormone jasmonic acid induces the formation of ER bodies (Matsushima et al. 2002 ; Hara-Nishimura and Matsushima 2003) as does the damage induced by pest chewing. Jasmonic acid is a well-known hormone that mediates wound response, induces resistance against insect/pathogen attack (McConn et al. 1997, Vijayan et al. 1998, Li et al. 2002, Chini et al. 2007, Sato et al. 2011) and regulates the expression of wound-inducible genes, such as the vegetative storage protein (VSP) genes (Leon et al. 2001, Lorenzo et al. 2004). But $\beta$ glucosidase is the main component of the ER body. Plants accumulate various glycoside molecules that are derived from secondary metabolism (Gachon , 2005, Ketudat and Esen, 2010). Several glycosides that are involved in defensive mechanisms, such as cyanogenic glucosidases , saponins, glucosinolates or DIMBOA (2,4-dihydroxy-7-methoxy-1,4-benzoxazin-3-one) glucoside (Mattiacci et al. 1995; Konno et al. 1999; Tattersall et al. 2001; Carpinella et al. 2005; Beekwilder et al. 2008; Morant et al. 2008). Most of these compounds are stored in the inactive state and become activated by the removal of glycone. $\beta$-Glucosidases hydrolyze these molecules into glycone and aglycone. Thus, they are essential for the production of toxic compounds that mediate plant defense against insects or fungi (Mattiacci et al. 1995; Tattersall et al. 2001; Ketudat and Esen 2010).

There are many results that show dynamic changes in organelles underlie the tolerance of plants to environmental stress. For example, morphological changes in vacuoles and small vesicular structures occur during salt and zinc ionic stress (Hamaji et al. 2009, Kawachi et al. 2009), vacuolar morphology in the endodermis is important for the shoot gravitropic response (Niihama et al. 2009). Therefore, focusing on organelle differentiation may reveal new insights into plant survival strategies (Hayashi and Nishimura 2009, Homi et al. 2009, Kamigaki et al. 2009, Mano et al. 2009, Nagano et al. 2008, Niihama et al. 2009, Sakamoto et al. 2009).

\section{DEFENSE BY NUCLEUS}

Communication between the cytoplasm and the nucleus is a fundamental feature conserved among eukaryotic systems. Transport of macromolecules across the nuclear envelope occurs through nuclear pore complexes (NPCs), which are composed of nucleoporins, and depends on import and export receptors, importins and exportins that respectively recognize nuclear localization signals (NLSs) and nuclear export signals on cargo proteins (Meier and Brkljacic, 2009). The Ras-related nuclear (Ran) protein provides the directionality of transport through its binding to GDP (cytoplasmic side) or GTP (nuclear side). Several cellular factors involved in the transport of macromolecules through the nuclear envelope, including nucleoporins, importins, and Ran-GTP-related components, are essential to mount an efficient immune response in response to different pathogens (Palma et al., 2005; Zhang and Li 2005; Tameling and Baulcombe 2007; Cheng et al., 2009). In addition, several reports strongly suggest that components of the NPC specifically mediate the transport of R proteins, immunity components, as well as TFs (transcription factors) and regulators that are necessary for activation of disease resistance (Garcia and Parker, 2009). These and other findings support the notion that specific modulation of the nuclear concentration of a set of defense regulators is crucial for the fine tuning of plant immunity (Susana 2012). A significant number of effectors proteins from different pathogens, including nematodes, fungi, viruses, bacteria, and oomycetes, are targeted to the nucleus by co-opting the host nuclear import machinery (Deslandes and Rivas 2011). This means that effectors may manipulate host transcription or directly target nuclear essential host components for the benefit of the pathogen. It has been additionally proposed that some effectors may affect histone modification and chromatin remodeling. Alternatively, nuclear translocation of effectors may affect sub cellular localization of their cognate $\mathrm{R}$ proteins in a process that is essential for R-protein-mediated plant immunity. (Susana 2011). 


\section{DEFENSE BY CHLOROPLAST}

It is nice to know that chloroplasts are a key defense organelle. Indeed The chloroplast is a vital component of photosynthetic cells in algae, and higher plants, since it is the organelle in which photosynthesis takes place (Cooper 2000). Photosynthesis is the major function of the chloroplast, but its roles clearly extend further than converting light energy into chemical energy. Actually the chloroplast, together with the nucleus, cell membrane, and endoplasmic reticulum (ER), plays a critical role during the establishment of plant immunity against microbial attack (Padmanabham and Dinesh-Kumar, 2010). It implies that during plant defense, interorganellar signaling to achieve a synchronized whole-cell response occurs (Serano et al., 2016).

Among cellular organelles chloroplast is an integrators for environmental signals and, more particularly, as mentioned earlier is a key defensive organelles (Serano et al., 2016)

The role of chloroplast in plant defense have been proved by evidence that show plants undergo an increased demand for photosynthesis during the interaction with pathogens, as the biosynthesis of pro-defense molecules and, more generally, the induction of defense responses requires energy that is provided through photosynthesis (Hammerschmidt 1999; Swarbrick and Lefert 2006). Moreover, virulent pathogens feed on plant carbon compounds, and some of them are able to use plant transporters of the SWEET family to promote sugar efflux, further increasing photosynthesis demand in host cells (Chen et al., 2010). However, instead of increased photosynthesis, several reports have revealed suppression of photosynthetic functions in infected plants, perhaps reflecting an active plant response to shut down carbon availability and limit pathogen growth or to favor the establishment of defense over other physiological processes, including photosynthesis, during pathogen attack (Padmanabham and Dinesh-Kumar 2010). on the other hand chloroplast is a major production site of prodefense molecules (Padmanabham and Dinesh-Kumar 2010). In fact chloroplasts play a central role in plant immunity by hosting biosynthesis of several key defense-related molecules, including hormones and secondary messengers (Padmanabham and Dinesh-Kumar 2010).

Consistent with the importance of a balanced production of pro-defense molecules during plant-pathogen interactions, pathogens have developed sophisticated molecular mechanisms to subvert their biosynthesis and subsequent signaling for their own benefit (Denance et al., 2013; Kazan and Lyons, 2014). The central role of hormones during plant-pathogen interactions is highlighted by the significant number of pathogenic microbes that are able to produce hormones or hormonemimicking molecules to disturb hormone homeostasis and cause disease (Robert et al., 2011) from for chloroplast.

\section{DEFENSE BY MITOCHONDRIA}

One of the most important defensive barriers of plants is mitochondria. After pathogen perception, mitochondria play an important role in the defense strategy of the plant cell, integrating and amplifying diverse signals such as salicylic acid, nitric oxide, reactive oxygen species (ROS) or pathogen elicitors. Signals perceived by mitochondria usually impact on their normal function, destabilizing the organelle, generating changes in respiration, membrane potential and ROS production. At this stage, mitochondria produce several signals influencing the redox state of the cell and promoting changes in the expression of nuclear genes by mitochondrial retrograde regulation. At more advanced stages, they promote programmed cell death in order to avoid pathogen propagation to the whole plant. So plant mitochondria take part in initiating response HR ( Jones 2000 ; Lam et al. 2001). Recent evidence indicates that plants and pathogens have evolved mechanisms to modulate the immune response by acting on mitochondrial functions (Amirsadeghi et al., 2007). On the other hand It is generally assumed that PTI (Pattern - Triggered Immunity) is a rapid response of the plant immune system and this first "cell reprogramming step" occurs during the first hour after plant-pathogen recognition. There are several evidences about the role of plant mitochondria during incompatible plant-pathogen interactions that include the perception of signals coming from the intercellular space or apoplast (Amirsadeghi et al., 2007).

Beside a role in the HR, mitochondria may represent an important intermediate between the perception of biotic stress and downstream responses such as the induction of defensive gene expression ( Jones 2000, Lam et al. 2001). Studies that have investigated this hypothesis are outlined below. Polyamines such as spermine are proposed to play a role during biotic stress responses. Spermine accumulates dramatically and in an $\mathrm{N}$-gene-specific manner in the apoplast of tobacco mosaic virus (TMV)-infected tobacco because of up regulation of genes involved in spermine biosynthesis (Yamakawa et al. 1998, Yoda et al. 2003). Accumulated polyamines are subsequently degraded in the apoplast by polyamine oxidize, generating $\mathrm{H}_{2} \mathrm{O}_{2}$ that may contribute to plant responses (Yoda et al. 2003). 


\section{DEFENSE By Golgi APPARATUS}

Glycosylation is a posttranslational modification reaction which is related to protein activity and protein secretory pathway in eukaryotic cells (Roth 2002). This essential reaction occurs in the endoplasmic reticulum and Golgi apparatus ( Kang et al., 2015). Although the glycosylation in the endoplasmic reticulum and Golgi apparatus has been known to regulate protein quality control, salt stress and cellulose biosynthesis, few evidences related to the roles of glycosylation in plant immunity have been reported (Kang et al., 2015). The role of Golgi apparatus in plant defense or plant immunity that is a pivotal role has been proved by studying about Arabidopsis thaliana mutants defective in glycosylation. The results showed that Arabidopsis mutants was more susceptible against Pseudomonas syringae pv. tomato DC3000 and Erwinia carotovora subsp. Carotovora compared to the wild type plant (Kang et al 2015). As mentioned above glycosylation occurs in endoplasmic reticulum and Golgi apparatus. In fact The glycosylated protein in the ER is translocated via vesicle to target or Golgi apparatus. In Golgi apparatus, the glycoprotein contains modification of $\mathrm{N}$-glycan chain by various glycolytic enzyme and glycotransferase. In contrast of mammals that complex $\mathrm{N}$-glycan are involved in different processes, including molecular recognition and signaling events, in plants complex N-glycan function is still largely unknown (Strasser 2014). In spite of the fact that complex N-glycans are ubiquitously present in plants (Wilson et al., 2001), their biological function is virtually unknown. The first mutant lacking complex $\mathrm{N}$-glycans was isolated more than two decades ago from Arabidopsis. These mutant showed that n-glycan mutants did not caused a substantial change in Arabidopsis growth or development when grown under long day conditions ( $16 \mathrm{~h}$-light/ $8 \mathrm{~h}$-dark) at $22^{\circ} \mathrm{C}$ (Strasser et al., 2007b). Up to now, the only evidence for a biological function of complex $\mathrm{N}$-glycans in Arabidopsis was found when cgl1 and other mutants were subjected to osmotic and salt stress (Kang et al., 2008). Reduced root growth on media containing high $\mathrm{NaCl}$ concentrations indicated that complex $\mathrm{N}$-glycans are implicated in tolerance to salt stress. However, a deeper understanding of complex $\mathrm{N}$-glycan function in Arabidopsis and studies that associate distinct complex N-glycan structures on individual glycoproteins with the enhanced salt sensitivity are completely missing (Strasser 2014).

\section{DEFEnSE By Peroxysomes}

As mentioned repeatedly, plants suffer from infections caused by fungi, bacteria, viruses and nematodes. Peroxysoms are one of the sub cellular organelles that play a substantial role in disease resistance. Peroxysomes are single membrane bound cellular organelles, present in almost all eukaryotic cells, which have an essentially oxidative metabolism (del Rio et al. 2002 ; Kaur et al. 2009). Peroxysomes contains a variety of enzymes that primarily function together to detoxify the toxins present in the cell and most notably hydrogen peroxide, which is the most common by product of cellular metabolism in living systems. These organelles contain enzymes that convert the hydrogen peroxide to water, rendering the potentially toxic substance safe for release back into the cells (del Rio et al. 2002 ; Nyathi and Baker 2006).

The roles of peroxysomes in plant biotic and abiotic defenses are becoming clearer (del Rio et al. 2006 ; Reumann et al. 2007; Palma et al. 2009; Corpas et al. 2010). About role of peroxysomes in plant defense for example we can express that plant peroxysomes contribute to extracellular defense mechanisms against fungi by preventing colonization. Upon fungal invasion peroxysomes migrate toward the site of invasion (Lipka, 2005). Under these conditions the myrosinase which is bound to the peroxysomal membrane, hydrolyzes indolic glucosinolates to antifungal defense compounds protecting plants against fungal entry (Bednarek 2009). Furthermore, certain benzylglucosinolates play a role in pathogen defense and are found in developing seeds and germinating seedlings (Graser et al., 2001). These active defense molecules are synthesized in the cytosol by transferring a benzoyl moiety from benzoyl-CoA to a hydroxylated aliphatic glucosinolate, though the precursor benzoyl-CoA is primarily produced from cinnamic acid via peroxysomal beta-oxidation (Baskar et al., 2012 ; Lee 2012 ; Qualley et al., 2012). Also Peroxysomes contain important enzymes and generate diverse metabolites that have a relevant role in the direct and indirect plant defense against herbivores (Shabab 2013). Different reports have shown the importance of ROS in herbivory related responses. Feeding of some pests on their hosts leads to considerably elevated ROS levels (Wu and Baldwin 2010). Another sample of increased ROS generation showed that mechanical wounding by herbivores was not sufficient to increase the amount of ROS but herbivory contribution was essential for that (Leitner et al., 2005). In another interesting study, an increase in the ROS levels in plants after pests attack was detected by Maffei et al., 2006.

\section{DEFENSE BY VACUOLES}

The central vacuole is one of the unique features of mature plant cells and presents the largest intracellular compartment in many higher plant tissues. Numerous studies carried out over the last twenty years have provided evidence that this organelle really behaves as a multifunctional compartment of plant cells. One of the roles of vacuoles in cells is plant defense response 
under condition of environmental stresses (Andreev 2001). In fact Plant cells have a large central vacuole that accumulates a variety of hydrolytic enzymes and antimicrobial compounds, raising the possibility that vacuoles play a role in plant defense (Hatsugai and Nishimura 2010). Plants, unlike animals, which have specialized defender cells and an adaptive immune system, have an innate immunity of each cell and produce systemic signals emanating from the infection site. On the other hand Plants have developed a complex immune system to resist pathogen attack, which includes rapid and localized cell death (hypersensitive response, HR), and stomatal closure (Dangl et al., 1996 ; Lam et al., 2001 ; Melotto et al., 2006 ; Mur et al., 2008). HR in plants is caused by proteases with cascade activity. At least eight cascade activities have now been measured in plant extracts, which were found using cascade substrates, and various cascade inhibitors can block many forms of plant programmed cell death (Zhang et al., 2010). A number of key players involved in HR have been identified (Greenberg and Yao, 2004; Gabriels et al., 2006; Gan et al., 2009; EK-Ramos et al., 2010); these studies have revealed that mammalian and plant cell death mechanisms share common morphological and biochemical features, including cytoplasm shrinkage, nuclear condensation, DNA laddering, and the release of cytochrome c from mitochondria (Sun et al., 1999 ; Sasabe et al., 2000 ; Kim et al., 2003 ; Ji et al., 2005). However, it remains unclear how signaling pathways lead to local HR, but not to whole-plant cell death, and how death occurs. Many studies have shown that HR in plants is regulated by cascade-like activity. However, no cascade homologue has been found in the past several years. So vacuolar-processing enzyme (VPE) has been determined to play important roles in plant immunity responses (Zhang et al., 2010). VPE localizes in the vacuolar membrane and mediates virus-induced hypersensitive cell death by regulating the collapse of this membrane (Hatsugai et al., 2004).

\section{CONCLUSION}

Photosynthesis is one of the most important processes that occur in green plants, alges and prokaryotic living organisms named cyanobacteria. In this pivotal process sunlight turn into chemical energy (food). In fact life on earth depends on this important process that the highest percentage of it's occurring in green plants. Briefly only plants can produce food for animals and humans. These supporter living organisms are sessile but they have to suffer from an extensive range of biotic or abiotic stresses. So they must equipped against injurious agents. Plants, unlike animals, which have specialized defender cells and an adaptive immune system, have an innate immunity of each cell and produce systemic signals emanating from the infection site. Generally plants campaign against harmful factors with different forms. Sometimes a plant is in contact with a pathogen to which is not a host, this form of defense is the most common form of resistance in nature, sometimes the host can to hinder the growth and/or the development of the pathogen. But this is important that Plant defense systems against pathogen invasion consist of multiple layers that means all of plant cell component such as: cell wall, plasma membrane, cytoplasm, endoplasmic reticulum, chloroplast, mitochondria, Golgi apparatus, peroxysomes and vacuoles.

\section{REFERENCES}

[1] Amirsadeghi S. Robson C. A. and Vanlerberghe G. C. 2007. The role of the mitochondrion in plant responses to biotic stress. Physiologia plantarum. $129: 253-256$

[2] Anant B. Manpreet K. and Anupam K. 2013. Recognition of plants by Leaf Image using Moment Invariant and Texture Analysis. International Journal of Innovation and Applied Studies. 3(1): 273 - 248

[3] Andreev I.M. 2001. Functions of the Vacuole in Higher Plant Cells. Russian Journal of Plant Physiology. 48(5): 672 - 680

[4] Baskar V. Gururani M.A. Yu J.W. Park S.W. 2012. Engineering glucosinolates in plants: current knowledge and potential uses. Applied Biochemistry and Biotechnology $168: 1694-1717$

[5] Bednarek P. 2009. A glucosinolate metabolism pathway in living plant cells mediates broad-spectrum antifungal defense. Science 323:101 - 106

[6] Beekwilder J. Van Leeuwen W. Van Dam N.M. Bertossi M. Grandi V. and Mizzi L. 2008. The impact of the absence of aliphatic glucosinolates on insect herbivory in arabidopsis. PLOS one. 3 : e2068

[7] Bell G. 1997. Selection. The Mechanism of Evolution. Chapman and Hall, New York.

[8] Bernays E.A. and Chapman R.F. 1994. Host-Plant Selection by Phytophagous Insects. Chapman and Hall. New York.

[9] Boller T. Felix G. A. 2009. Renaissance of elicitors: perception of microbe-associated molecular patterns and danger signals by pattern-recognition receptors. Annual Review of Plant Biology. 60: $379-406$

[10] Bryant D.A. and Frigaard N.U. 2006. Prokaryotic photosynthesis and phototrophy illuminated. Trends in Microbiology. 14(11): 488 $-496$.

[11] Carpinella M.C. Ferrayoli C.G. Palacios S.M. 2005. Antifungal synergistic effect of scopoletin, a hydroxycoumarin isolated from Melia azedarach L. fruit. $53: 2922-2927$.

[12] Chen L.Q. Hou O.K. Lalonde S. 2010. Sugar transporters for intercellular exchange and nutrition of pathogens. Nature $468: 527-$ 532. 
[13] Cheng Y.T. Germain H. Wiermer M. Bi D. Xu F. Garcia A.V. Wirthmueller L. Despres C. Parker J.E. Zhang Y. 2009. Nuclear pore complex component MOS7/Nup88 is required for innate immunity and nuclear accumulation of defense regulators in Arabidopsis. Plant Cell 21: $2503-1516$.

[14] Chini A. Fonseca S. Fernandez G. Chico J.M. Lorenzo O. 2007. The JAZ family of repressors is the missing link in jasmonate signalling. Nature. $488: 666-671$.

[15] Cooper G.M. 2000. The Cell: a moleculat approach, 2nd edn. Sunderland, M.A. Sinauer Associates.

[16] Corpas F.J. Palma J.M. Leterrier M. del Rio L.A. Barroso J.B. 2010. Nitric oxide and abiotic stress in higher plants. In: Hayat S, Mori M, Pitchel J, Ahmad A (eds) Nitric oxide in plant physiology. Wiley-VCH, Weinheim. pp 51 - 63.

[17] Dangle J.L Dietrich R.A. and Richberg M.H. 1996. Death don't have no mercy: cell death programs in plant-microbe interactions. Plant Cell. $8: 1793$ - 1807.

[18] David H. and Easwaramoorthy S. 1988. Physical resistance mechanisms in insect plant interaction. In: Dynamics of Insects - Plant Interactions: Recent Advances and Future Trends (T. N. Ananthakrishnan \& A. Raman, eds), pp. 45 - 70 . Oxford \& IBH Publishers, New Delhi.

[19] Del Rio L. A. Corpas F.J. Sandalio L.M. Palma J.M. Gomez M. and Barroso J.B. 2002. Reactive oxygen species, antioxidant systems and nitric oxide in peroxysomes. Journal of Experimental Botany. 53: $1255-1572$.

[20] Del Rio L.A. Sandalio L.M. Corpas F.J.Palma J.M. Barroso J.B. 2006. Reactive oxygen species and reactive nitrogen species in peroxisomes. Production, scavenging, and role in cell signaling. Plant Physiology. 141:330 - 335.

[21] Denance N. Sanchez-Vallet A. Goffner D. Molina A. 2013. Disease resistance or growth: the role of plant hormones in balancing immune responses and fitness costs. Frontiers in Plant Science. $4: 155$.

[22] Deslandes L. Rivas S. 2011. The plant cell nucleus: a true arena for the fight between plants and pathogens. Plant Signal Behavior 6: $42-48$.

[23] Dhan Pal S. and Arti S. 2005. Disease and insect resistance in plants. En field (N.H.) Science Publ. Page 44.

[24] Dhume S.T. Adamsburton, C.R. and Laine R.A. 1993. Inhibition of invasion of human red blood cells by Plasmodium falciparum using erythroglycan, chitooligosaccharides, maltooligosaccharides and their neoglycoproteins. Faseb Journal 7:A1253.

[25] Dickson W.C. 2000. Integrative Plant Anatomy. Harcourt Academic Press. Chapter 10. pp. 359 - 380.

[26] Doughari J.H. 2015. An Overview of Plant Immunity. Plant Pathology \& Microbiology. 6 (11): 2 - 11.

[27] Duffey S.S. 1986. Plant glandular trichomes: their partial role in defense against insects. In: Insects and the Plant Surface (B. Juniper \& T. R. E. Southwood, eds), pp. 151 - 172 Edward Arnold, London.

[28] Ebel J. and Cosio E. 1994. Elicitors of plant defense responses. Int. Rev. Cytol. 148, 1 - 36.

[29] EK-Ramos M.J. Avila J.Cheng C. Martin G.B. Devatenne T.P. 2010. The T-loop extension of the tomato protein kinase AvrPtodependent Pto-interacting protein 3 (Adi3) directs nuclear localization for suppression of plant cell death. Journal of Biological Chemistry. doi:10.1074/jbc.M110.117416.

[30] Esseling-Ozdona A. Houtman D. Van Lammeren A.A.M. Eiser E. and Emons A.M.C. 2008. Hydrodynamic flow in the cytoplasm of plant cells. Journal of Microscopy. 231(2): $274-283$.

[31] Gabriels S.E.J. Takken F.L.W. Vossen J.H. 2006. cDNA-AFLP combined with functional analysis reveals novel genes involved in the hypersensitive response. Molecular Plant-Microbe Interactions 19: 567 - 576.

[32] Gachon C.M.M. langlois-Meurinne M. Saindrenan P. 2005. Plant secondry metabolism glycosyltransferases: The emerging functional analysis. Trends Plant Sciences. $10: 1360-1385$.

[33] Gan Y.Z. Zhang L.S. Zhang Z.G. Dong S.M. Li J. Wang Y.C. Zheng X.B. 2009. The LCB2 subunit of the sphingolip biosynthesis enzyme serine palmitoyltransferase can function as an attenuator of the hypersensitive response and Bax-induced cell death. New Phytologist 181: $127-146$.

[34] Garcia A.V. and Parker J.E. 2009. Heaven's Gate: nuclear accessibility and activities of plant immune regulators. Trends in Plant Science. 14: $479-487$.

[35] Gianinazzi S. and Ahl P. 1983. The genetic and molecular basis of b-proteins in the genus Nicotiana. Netherlands Journal of Plant Pathology. 89(6): 275 - 281.

[36] Graser G. Oldham. N.J. Brown. P.D. Temp, U, Gershenzon. J. 2001. The biosynthesis of benzoic acid glucosinolate esters in Arabidopsis thaliana. Phytochemistry. $57: 23-32$.

[37] Greenberg J.T. Yao N. 2004. The role and regulation of programmed cell death in plant pathogen interactions. Cell Microbiology 6 : $201-211$.

[38] Hahn M. Bucheli P. Cervone F. Doares S. O’Neill R. Darvill A. and Albersheim P. 1989. Roles of cell wall constituents in plantpathogen interactions. In Plant-Microbe Interactions: Molecular and Genetic Perspectives, T. Kosuge and E. Nester, eds (New York: McGraw-Hill), pp. 131-181.

[39] Hahn M. Mendgen K. 2001. Signal and nutrient exchange at biotrophic plant-fungus interfaces. Current Opinion in Plant Biology. 4: $322-327$.

[40] Hamaji K. Nagira M. Yoshida K. Oda Y. Uemura T. 2009. Daynamic aspects of ion accumulation by vesicle traffic under salt stress in Arabidopsis. Plant Cell Physiology. $50: 2023$ - 2033.

[41] Hammerschmidt R. 1999. Induced disease resistance: how do induced plants stop pathogens? Physiological and Molecular Plant Pathology. $55: 77-84$.

[42] Hamann T. Bennett M.Mansfield J. Somerville C. 2009. Identification of cell-wall stress as a hexose-dependent and osmosensitive regulator of plant responses. Plant Journal. 57 : 1015 - 1026. 
[43] Hara-Nishimura I. and Matsushima R. 2003. A wound-inducible organelle derived from endoplasmic reticulum: A plant strategy against environmental stress? Current Opinion in Plant Biology. 6: 583-588.

[44] Hatsugai N. and Nishimura I.H. 2010. Two vacuole-mediated defense strategies in plants. Plant Signaling \& Behavior. 5(12): $1568-$ 1570 .

[45] Hatsugai N. Kuroyanagi M. Yamada K. Meshi T. Tsuda S. Kondo M. Nishimura M. Hara Nishimura I. 2004. A plant vacuolar protease, VPE, mediates virus-induced hypersensitive cell death. Science. $305: 855-858$.

[46] Hayashi M. Nishimura M. 2009. Frontiers on resarch on organell differentiation. Plant Cell Phsiology. 50 : 1995 - 1999.

[47] Heide-Jorgensen H.S. 1991. Cuticle development and ultrastructure-Evidence for a procuticle of high osmium affinity. Planta 183: 511-519.

[48] Herman E.M. Endoplasmic reticulum bodies: solving the insoluble. 2008. Current Opinion in Plant Biology. 11: 672 - 679.

[49] Homi S. Takechi K. Tanidokoro K. Sato H. Takio S. Takano H. 2009. The pepdidoglycan biosynthesis gene MurA and MraY are related to chloroplast division in the moss. Phycomitrella patent. Plant Cell Physiology. 50 : 2047 - 2056.

[50] James M. E. and Gitta C. 2011. The Role of the Plasma Membrane H+-ATPase in Plant-Microbe Interactions. Molecular Plant. 4(3): $416-427$.

[51] Jeffree C.E. 1986. The cuticle, epicuticular waxes and trichomes of plants, with reference to their structure, function and evolution. In: Insects and the Plant Surface (B. Juniper \& T. R. E. Southwood, eds). pp. 23 - 64. Edward Arnold, London.

[52] Ji R. Zhang Z.G. Wang X.B. Zheng X.B. 2005. Phytophthora elicitor PB90 induced apoptosis in suspension cultures of tobacco. Chinese Science Bulletin. 50:435 - 439.

[53] Johnson B. 1975. Plant pubescence: an ecological perspective. The Botanical Review Journal 41: 233 - 258.

[54] Jones A. 2000. Does the plant mitochondrion integrate cellular stress and regulate programmed cell death? Trends Plant Science 5 : $225-230$

[55] Juniper B. and Southwood T.R.E. 1986. Insects and the Plant Surface. Edward Arnold, London..

[56] Kamigaki A. Kondo M. Mano S. Hayashi M. and Nishimura M. 2009. Suppression of peroxisome biogenesis factor 10 reduces cuticular wax accumulation by disrupting the ER network in Arabidopsis thaliana. Plant Cell Physiology. 50: 2034 - 2046.

[57] Kang B. S. Baek J.H. Macoy D.M. Chakraborty R. Cha J.Y. Hwang D.J., Lee Y.L., Lee S.Y. Kim W.Y. and Kim M.G. 2015. N-Glycosylation Process in Both ER and Golgi Plays Pivotal Role in Plant Immunity. Journal Plant Biology. 58 : 374 - 382.

[58] Kang J.S. Frank J. Kang C.H. Kajiura H. Vikram M. Ueda A. Kim S. Bahk J.D. Triplett B. Fujiyama K. Lee S.Y. von Schaewen A. Koiwa H. 2008. Salt tolerance of Arabidopsis thaliana requires maturation of N-glycosylated proteins in the Golgi apparatus. Proceeding of the National Academy of Scienses of the United States of America USA. $105: 5933$ - 5938.

[59] Kaur N. Reumann S. Hu J. 2009. Peroxisome biogenesis and function. In: The Arabidopsis book. The American Society of Plant Biologists. Rockville. pp $1-41$.

[60] Kawachi M. Kobae y. Tomioka R. Lee Y. Maeshima M. 2009. A mutant strain Arabidopsis thalina that lacks vacuolar membrane zinc transporter MTP1 revealed the latent tolerance to excessive zinc. Plant Cell Physiology. 50 : 1159 - 1170.

[61] Kazan K. Lyons R. 2014. Intervention of phytohormone pathways by pathogen effectors. The Plant Cel.1 26 : 2285 - 2309.

[62] Kerstiens G. ed 1996a. Plant Cuticles: An Integrated Functional Approach. Oxford, UK: BIOS Scientific Publishers.

[63] Kerstiens G. 1996. b Signalling across the divide: A wider perspective of cuticular structure -function relationships. Trends Plant Sci. 1: 125-129.

[64] Ketudat C. J.R. Esen A. 2010. $\beta$-Glucosidases. Cellular and Molecular Life Sciences. 67: 3389 - 3405.

[65] Kim M. Ahn J.W. Jin U.H. Chai D. Poek K.H. Pai H.S. 2003. Activation of the programmed cell death by inhibition of proteasome function in plant. Journal of Biological Chemistry $278: 19406-19415$.

[66] Konno K. Hirayama C. Yasui H. Nakamura M. 1999. Enzymatic activation of oleuropein: a protein crosslinker used as a chemical defense in the privet tree. Proceedings of the National Academy of Sciences. $96: 9159-9164$.

[67] Kumamaru T. Uemura Y. Lnoue Y. Takemoto Y. Siddiqui S.U. Ogawa M. 2010. Vacuolar processing enzyme plays an essential role in the crystalline structure of glutelin in rice seed. Plant Cell Physiology. 51: 38 - 46.

[68] Lam E. Kato N. and Lawton M. 2001. Programmed cell death, mitochondria and the plant hypersensitive response. Nature. $411: 848$ $-853$.

[69] Lee S. 2012. Benzoylation and sinapoylation of glucosinolate R-groups in Arabidopsis. Plant Journal. 72 : 411 - 422.

[70] Leitner M. Boland W.Mithofer A. 2005. Direct and indirect defences induced by piercing-sucking and chewing herbivores in Medicago truncatula. New Phytologist. 167:597 - 606.

[71] Leon J. Rojo E. Sanchez-Serrano J.J. 2001. Wound signalling in plants. Journal of Experimental Botany. $52: 1-9$.

[72] Levin D.A. 1973. The role of trichomes in plant defence. The Quarterly Review of Biology. 48: 3 - 15.

[73] Li L. Li C. Lee G.I. Howe G.A. 2002. Distinct role for jasmonate synthesise and action in the systemic wound response of tomato. Proceedings of the National Academy of Sciences of the United States. 6416 - 6421.

[74] Lipka V. 2005. Pre- and postinvasion defenses both contribute to nonhost resistance in Arabidopsis. Science. $310: 1180$ - 1183.

[75] Lorenzo O. Chico J.M. Sanchez-serrano J.J. Solano R. 2004. JASMONATE INSENSITIVE 1 encodes a MYC transcription factor essential to discriminate between different jasmonate-regulated defense responses in Arabidopsis. Plant Cell. 16 : 1938 - 1950.

[76] McConn M. Creelman R.A. Bell E.Mullet. J.E. and Browse J. 1997. Jasmonate is essential for insect defense in Arabidopsis. Proceedings of the National Academy of Sciences of the United States. 94: 5473 - 5457. 
[77] Maffei M.E. Mithofer A. Arimura G. Uchtenhagen H. Bossi S. Boland W. 2006. Effects of feeding Spodoptera littoralis on lima bean leaves. III. Membrane depolarization and involvement of hydrogen peroxide. Plant Physiol Journal. 140 : 1022 - 1035.

[78] Malinovsky F.G. Fangel, J.U. and Willats W.G. 2014. The role of the cell wall in plant immunity. Frontiers in Plant Science. 5: $1-$ 12.

[79] Mano S. Miwa T. Nishikawa S. Mimura T. and Nishimura M. 2009. The Plant Organelles Database 2 (PODB2): an updated resource containing movie data of plant organelle dynamics. Plant Cell Physiology. 52: 244 - 253.

[80] Mario S. Fania C. Martha T. Floriane L. H. and Jean-Pierre M. 2014. Frontiers in Plant Science. 5: 1 - 16.

[81] Marquis R.J. 1992. The selective impact of herbivory. In: Plant Resistance to Herbivory and Pathogens. Ecology, Evolution and Genetics (R. S. Fritz \& E. L. Simms, eds). pp. 301 - 325. The University of Chicago Press, Chicago.

[82] Matsushima R. Hayashi Y. Shimada T. Nishimura, M. and Hara-Nishimura I. 2002 . An endoplasmic reticulum-derived structure that is induced under stress conditions in Arabidopsis. Plant Physiol. 130 1807-1814.

[83] Mattiacci L. Dick M. Posthumus M.A. 1995. $\beta$ - Glucosidase: an elicitor of herbivore-induced plant odor that attracts host-searching parasitic wasps. Proceedings of the National Academy of Science of the United States of America. 92: 2036 - 2040.

[84] Meier I. Brkljacic J. 2009. The nuclear pore and plant development. Current Opinion in Plant Biology. $12: 87$ - 95.

[85] Melotto M. Underwood W. Koczan J.Nomura K. He. S.Y. 2006. Plant stomata function in innate immunity against bacterial invasion. Cell 126: $969-980$.

[86] Milewski A.V. Truman P. Young T.P. and Madden M. 1990. Thorns as induced defenses: experimental evidence. Oecologia. $86: 70$ -75 .

[87] Monart A.v. Jorgensen K. Jorgensen C. Paquette S.M. Sanchez-Perez R. Moller B.L. 2008. $\beta$ Glucosidases as detonators of plant chemical defense. Phytochemistry. $69: 1795-1813$.

[88] Mur L.A. Kenton P Lloyd A.J Ougham H. Prats E. 2008. The hypersensitive response; the centenary is upon us but how much do we know? Journal of Experimental Botany $59: 501-520$.

[89] Nagamine M. Okita T.W. 2011. A role for the cystein-rich 10Kda prolamin in protein body formation in rice. Plant Cell Physiology. 52: $1003-1016$.

[90] Nagano A.J. Fukao Y. Fujiwara, M. Nishimura M. and Hara- Nishimura I. 2008. Antagonistic jacalin-related lectins regulate the size of ER body-type b-glucosidase complexs in Arabidopsis thaliana. Plant Cell Physiology. 49 : 969 - 980.

[91] Niihama M. Takemoto N. Hashiguchi Y. Tasaka M. Morita M.T. 2009.. ZIP gense encode proteins involved in memberane trafficking of the TGN - PVC/ vacuoles. Plant Cell Physiology. $50: 2057-2086$.

[92] Nyathi Yand Baker A. 2006 Plant peroxisomes as a sourse of signalling molecules. Biochimica et Biophysica Acta. 1763 : $1478-$ 1495.

[93] Padmanabhan M.S. Dinesh - Kumar S.P. 2010. All hands on deck - the role of Chloroplasts, endoplasmic reticulum, and nucleus in driving plant innate immunity. Molecular Plant - Microb Interactions. 23: 1368 - 1380.

[94] Palma K. Zhang Y. Li. X. 2005. An importin alpha homolog, MOS6, plays an important role in plant innate immunity. Current Biology 15: 1129 - 1135 .

[95] Palma J.M. Corpas F.J. del Rio L.A. 2009. Proteome of plant peroxisomes: new perspectives on the role of these organelles in cell biology. Proteomics $9: 2301-2312$.

[96] Patrick S. Martine S. Ulrich R. Antony B. Pappachan Kolattukudy J. P M. and Christiane N. 2000. Transgenic Arabidopsis Plants Expressing a Fungal Cutinase Show Alterations in the Structure and Properties of the Cuticle and Postgenital Organ Fusions. The Plant Cell. 15(2): $721-738$

[97] Peter A.J. Shanower T.G. and Romeis J. 1995. The role of plant trichomes in insects resistance: a selective review. Phytophaga (Madras) 7: $41-64$.

[98] Qualley A.V. Widhalm J.R. Adebesin F. Kish C.M. Dudareva N. 2012. Completion of the core oxidative pathway of benzoic acid biosynthesis in plants. Proceeding of the National Academy of Scienses of the United States of America USA. 109 : 16383 16388.

[99] Reumann S. Babujee L. Ma C. Wienkoop S. Siemsen T. Antonielli M. Rasche N. Luder F. Weckwerth W.Jahn O. 2007. Proteome analysis of Arabidopsis leaf peroxisomes reveals novel targeting peptides, metabolic pathways, and defense mechanisms. Plant Cell 19: 3170- 3193.

[100] Robert-Seilaniantz A. Grant M. Jones J.D.G. 2011. Hormone crosstalk in plant disease and defense: more than just jasmonatesalicylate antagonism. Annual Review of Phytopathology 49 : 317-343.

[101] Rodriguez E. Healy P.L. and Mehta I. eds. 1984. Biology and Chemistry of Plant Trichomes. Plenum, New York.

[102] Romeis J. Shanower T.G. and Peter A.J. 1999. Trichomes on Pigeonpea [Cajanus cajan (L.) Millsp.] and two wild Cajanus spp. Crop Science. 39: $564-569$.

[103] Roth J. 2002. Protein N-glycosylation along the secretory pathway: relationship to organelle topography and function, protein quality control, and cell interactions. Chemical Reviews (ACS Publications) $102: 285-305$.

[104] Roy B.A. Stanton M.L. and Eppley S.M. 1999. Effects of environmental stress on leaf hair density and consequences for selection. Journal of Evolutionary Biology . 12: 1089 - 1103.

[105] Ryan C. 1988. Oligosaccharides as recognition signals for the expression of defensive genes in plants. Biochemistry. $27: 8879$ 8883.

[106] Saa-Silva S. Brown P. H. Ponchet M. (eds). 2013. First World Congress on the Use of Biostimulants in Agriculture. Leuven: International Society of Horticultural Science. 
[107] Sakamoto W. Uno Y. Zhang Q. Miura E. Kato Y. and Sodmergen. 2009. Arrested differentiation of proplastids into chloroplasts in variegated leaves characterized by plastid ultrastructure and nucleoid morphology. Plant Cell Physiology. $50: 2069$ - 2083.

[108] Sasabe M. Takeuchi K. Kamoun S. 2000. Independent pathways leading to apoptotic cell death, oxidative burst and defence gene expression in response to elicitin in tobacco cell suspension culture. European Journal of Biochemistry 267: 5005 - 5013.

[109] Sato C. Aikawa K. Sugiyam, S. Nabeta K, Masuta C. and Matsuura H. 2011. Distal transport of exogenously applied jasmonoylisoleucine with wounding stress. Plant Cell Physiology. 52: 509 - 517.

[110] Satoh - Cruz M. Crofts A.J. Takemoto - Kanu Y. Sugino A. Washida H. Crofts N. 2010. Protein disulfide isomerase like - $1-1-$ participates in the maturation of prolutelin with the endoplasmic reticulum in rice endosperm. Plant Cell Phsiology. $51: 1581$ - 1583.

[111] Serrano I. Audran C. and Rivas S. 2016. Chloroplasts at work during plant innate immunity. Journal of Experimental Botany. 67(13): $3845-3854$.

[112] Shabab M. 2013. Role of Plant Peroxisomes in Protection Against Herbivores. Subcellular Biochemistry. 69 : 315 - 328.

[113] Staehelin L.A. 1996 The plant ER: a dynamic organelle composed of a large number of discrete functional domains. Plant Journal. 11: $1151-1165$.

[114] Strasser R. Bondili J. Vavra U. Schoberer J. Svoboda B. Glossl J. 2007b. A uniquebeta 1,3-galactosyltransferase is indispensable for the biosynthesis of N-glycans containing Lewis a structures in Arabidopsis thaliana. Plant Cell 19: 2278 - 2292 .

[115] Strasser R. 2014. Biological significance of complex N-glycans in plants and their impact on plant physiology. Frontiers in Plant Science. 5 (363): $1-6$.

[116] Sun Y. Zhao Y. Hong X. Zhai Z. 1999. Cytochrome c release and caspase activation during menadione-induced apoptosis in plants. FEBS Letters $42: 317-321$

[117] Susana R. 2012. Nuclear Dynamics during Plant Innate Immunity. Plant Physiology. 158: 87 - 94.

[118] Swarbrick P.J. Lefert P.S. 2006. Metabolic consequences of susceptibility and resistance (race-specific and broad-spectrum) in barley leaves challenged with powdery mildew. Plant, Cell and Environment 29:1061 - 1076.

[119] Tameling W.I. Baulcombe D.C. .2007. Physical association of the NB-LRR resistance protein Rx with a Ran GTPase-activating protein is required for extreme resistance to Potato virus X. Plant Cell 19: $1682-1694$.

[120] Tattersall D.B. Bak S. Jones P.R. Olsen C.E. Nielsen J.K. Hansen M.L. 2001. Resistance to an herbivore through engineered cyanogenic glucoside synthesis. Science 293: $1826-1828$.

[121] Vijayan P. Shockey J. Levensque C.A. Cook R.J. Browse J. 1998. A role of jasmonic acid in pathogen defense of Arabidopsis. Proceedings of the National Academy of Sciences of the United States. $95: 7209-7214$.

[122] Walker D.B. and Bruck D.K. 1985. Incompetence of stem epidermal cells to dedifferentiate and graft. Canadaian Journal of Botany. 63: 2129-2132.

[123] Ward J. Maser M. JI P. S. 2009. Plant ion channels: gene families, physiology, and functional genomics analyses. Annual Review of Physiology. 71: $59-82$.

[124] Wilson I. Zeleny R. Kolarich D. Staudacher E. Stroop C. Kamerling J. 2001. Analysis of Asn-linked glycans from vegetable foodstuffs : widespread occurrence of Lewis a, core alpha1,3-linked fucose andxylo sesubstitutions. Glycobiology. 11: 261 - 274.

[125] Woodman R.L. and Fernandes, G.W. 1991. Differential mechanicaldefense: herbivory, evapotranspiration, and leaf hairs. Oikos 60: $11-19$.

[126] Wu J. Baldwin I.T. 2010. New insights into plant responses to the attack from insect herbivores. Annual Review of Genetics. $44: 1$ -24 .

[127] Yamakawa H. Kamada H. Satoh M. Ohashi Y. 1998 Spermine is a salicylate-independent endogenous inducer for both tobacco acidic pathogenesis-related proteins and resistance against tobacco mosaic virus infection. Plant Physiology 118: 1213 - 1222.

[128] Yasuda H. Hiroses S. Kawakatsu T. Wakasa Y. Takaiwa F. 2009. Overexpression of Bip has inhibitory effects on the accumulation of seed storage protein in endosperm cells of rice. Plant Cell Physiology. 50: $1532-1543$.

[129] Yoda H. Yamaguchi Y. Sano H. 2003 Induction of hypersensitive cell death by hydrogen peroxide produced through polyamine degradation in tobacco plants. Plant Physiol 132: $1973-1981$.

[130] Zhang Y. Li X. 2005. A putative nucleoporin 96 is required for both basal defense and constitutive resistance responses mediated by suppressor of npr1-1,constitutive 1. Plant Cell 17: 1306 - 1316.

[131] Zhang H, Zheng X and Zhang Z. 2010. The role of vacuolar processing enzymes in plant immunity. Plant Signaling \& Behavior 5(1): $1565-1567$. 